\title{
Research of the structure and function of Ordinary Landing Craft
}

\author{
Liu Chao-fan ${ }^{1, a}$ Zhang shun ${ }^{2, b}$ Zheng Yuan-zhou*3,c \\ ${ }^{1}$ School of Navigation, Wuhan University of Technology, Wuhan 430036, China; \\ ${ }^{2}$ School of Navigation, Wuhan University of Technology, Wuhan 430036, China; \\ ${ }^{3}$ School of Navigation, Wuhan University of Technology, Wuhan 430036, China; \\ Hubei Key Laboratory of Inland Shipping Technology, Wuhan 430036, China \\ a1115952594@qq.com,, 3264899894@qq.com, ${ }^{\text {'zhengyuanzhou0909@163.com }}$
}

Key words: Landing craft; Analogy method. Facility planning and design method; Design calculation method; Software application method; Simulation experiment

\begin{abstract}
Rich in natural resources, the south China sea area islands is various, but the area is not large, dense distribution is normal landing craft in the process of using the shortfalls, stability, speed and endurance greatly affects the work efficiency of the construction of the south China sea, thus put forward a feasible multifunctional landing craft appear very important. The "new multifunctional crawler type high-efficiency hydrofoil landing craft" proposed by this research project has great improvement in structure and function. This paper by looking at the data uses analogy method to avoid the defect of other devices or equipment, then through facilities planning and design method for "multifunctional crawl type high-efficiency hydrofoil landing craft" to carry on the reasonable structure design and reasonable configuration, and then through the design calculation method combining the calculation formula of design structure and related implementation maximum design optimization in theory, then through software application method of graphic design and analysis, finally through the simulation experiment to test design, and aims at the problems of feedback and optimization. The research team of this paper has strong theoretical and practical value to solve the current limitation of the sea performance and land travel of ordinary landing craft.
\end{abstract}

\section{Introduction}

The sea is the natural link between countries' trade and cultural exchanges. Under the background of China becoming the world's second largest economy and the global political and economic landscape is interconnected, in September and October 2013, the chairman of China Xi Jinping has successively proposed a major initiative to jointly build One Belt And One Road, during his visit to central Asia and southeast Asia, and it is highly concerned by the international community. Strategic partners of " 21 st century maritime silk road" ,connect the market chains of major economic sectors such as ASEAN, South Asia, north Africa and Europe. Because ASEAN is located at the crossroads of the maritime silk road and is a must, it is the first development goal of the "21st century maritime silk road" strategy which making the south China sea an important development goal for China ${ }^{[1]}$.

During the construction of the south China sea, the search and rescue of accidents and casualties 
is often dependent on helicopters for small matter transportation between islands and islands land. It is also likely that more convenient vehicle will be required in that exploration of the unknown island, land forms and nearby sea areas. An unknown danger may result if only ordinary ships or helicopters are dispatched ,and it is difficult to treat when there are accidental casualties. At this time, it is very important to improve the construction efficiency of the south China sea with good performance and convenient and convenient sea transportation.

"High speed, smooth" is the most promising maritime transport tool or military transport platform in the 21 st century, it is a development trend of the present high performance ship to "hybridize" different types of high-performance ships to form a new composite ship with a view to achieving better performance. The average landing craft is unsatisfactory in terms of stability, speed and endurance. The air cushion landing craft is more expensive than the ordinary landing craft, although both speed and endurance are improved. In recent years, domestic and foreign scholars and the relevant departments for ability evaluation made a lot of research, and achieved some results. In the late 1950s, our country started the application of air cushion technology research and development of the national organization strength. More than 40 units began to theory research and model test, beginning in 1982, air cushion vehicle into the practical phase in our country ${ }^{[2]}$. In foreign countries, the first country to develop hovercraft was Britain. As early as the mid-19th century, Cockerel established the theory of air cushion. He found that if air was used as a "cushion" between ships and water, it could reduce the drag significantly, thus increasing the speed of the ship. In 1959, the first British hovercraft SRNI crossed the English channel successfully; In October 1977, the U.S. naval coastal systems research center in Florida built two 160t-class air cushion vehicles, JEFF(A) and JEFF(B); In 1970, Russia's first generation of called "Carrie" the medium-sized hovercraft ${ }^{[3]}$.It can be seen that relevant experts and maritime units have some research on landing craft, but there is no mature solution for the high cost of hovercraft. According to structure and function of the landing craft problem, this paper through the analogy access various other normal landing craft, avoiding the defects of other devices or equipment, through the facilities planning and design method for "multifunctional crawler type high-efficiency hydrofoil landing craft"to carry on the reasonable structure design and reasonable configuration, and then the design calculation method combining the calculation formula of design structure and related implementation maximum design optimization in theory, then through software application method of graphic design and analysis, finally through the simulation experiment to test design, and aims at the problems of feedback and optimization. Designed in this paper, based on the normal landing craft and equipment structure transform, effectively solve the current normal landing craft performance facing the sea and land traffic restrictions, has a good practicability.

\section{The design of landing craft}

\section{The choice of ship type and the design of the tank Ship type and material selection}

This paper selects a catamaran structure, which is a ship composed of two independent ships. The typical catamaran is composed of two long thin slices with a deck attached to the upper part of the body, and a power plant, power station and other equipment are installed in the body, and the upper part of the deck bridge is installed. The body of a high-speed catamaran is usually shaped in the shape of a sharp taper and the tail end of a square tail or a half square tail. Compared with ordinary single ship catamaran, it has a large deck area, small wave making, good stability, good maneuverability, the characteristics of the rolling period short ${ }^{[4]}$, so after many considerations, this 
paper design the multifunctional landing craft adopts the structure of a catamaran. Many of the advantages of high-speed catamaran are good for landing craft, such as :(1) low resistance when high speed sailing. (2) excellent initial stability. (3) good maneuverability and maneuverability. (4) good anti-sinking ability. (5) a good living environment and the spacious deck area (6) Good living environment and spacious deck area. (7) When loading and unloading cargo, it is not necessary to carry out the loading and unloading strictly according to the stowage schedule. (8) compared with the same displacement mono-hull ship, it is shallow draft and it is more suitable for sailing in shallow water ${ }^{[5]}$.

"Multifunctional crawler type high-efficiency hydrofoil landing craft" that this article mentioned is equipped with a retractable water wing on the basis of the catamaran., It enables the normal landing craft to maintain the excellent performance of the catamaran, with the rapidity of the hydrofoil. And it designed a buoyant tank. And after landing, it uses the crawler as the driving system on the shore.as shown in figure 1:

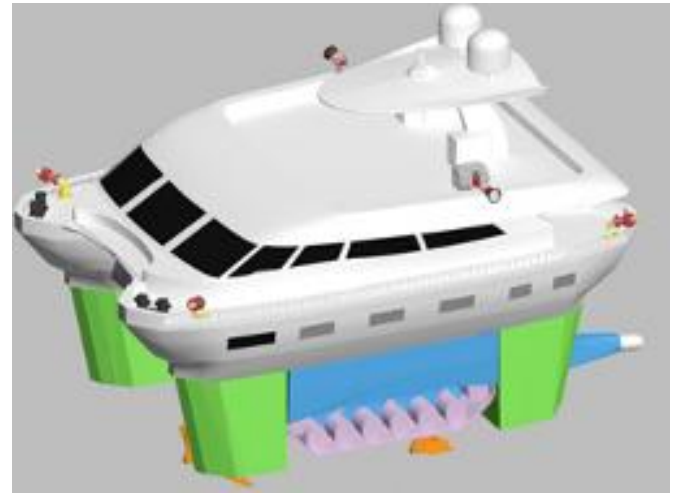

FIG. 1 multifunctional crawler mounted high-efficiency hydrofoil landing craft.

In terms of materials, it is mainly made of aluminum alloy and titanium and its alloys. Other materials are auxiliary.

\section{The design of the adjustable buoyancy tank}

When the landing craft is in the water, the crawler will increase the resistance in the water, and its weight is large, which has a great influence on the stability and rapidity of landing craft. In order to overcome this problem, we designed an adjustable buoyancy tank with a streamlined design.

When working in buoyancy tank, it provides buoyancy for landing craft through devolution. When landing craft arrives, the working status of the buoyancy tank ends, and the landing craft will be prepared by the climbing of the guide rail.

Due to landing craft design in this paper on the surface of the water and land, so the material of hull should satisfy the choice of low density, corrosion resistance, high strength, easy processing characteristics of glass fiber reinforced plastic, in accordance with the above characteristics. Therefore, the buoyancy tank is made of fiberglass as the material.

\section{Determination of main parameters of landing craft}

\section{Determination of the main length of amphibious landing craft}

The length of the amphibious landing craft can be calculated by the following formula:

$$
L_{W 1}=L_{a}+L_{P}+L_{f}
$$

where: $L_{W 1}-----$ The length of the waterline of an amphibious boat, the unit is $\mathrm{m}$;

$L_{\mathrm{a}}$------ The length of the aft peak of the amphibious craft, the unit is $\mathrm{m}$, and $L_{\mathrm{a}}=0.08 L_{W 1}$; 
$L_{p^{------~}}$ The length of the cabin of the amphibious craft, the unit is $\mathrm{m}, L_{P}=R_{O W}+2.8, R_{O W}$ is the number of rows along the captain's direction;

$L_{f}$----- The length of the first peak of the amphibious craft, the unit is $\mathrm{m}$, and $L_{f}=0.10 L_{w 1}$.

The total length of the amphibious boat is based on the following formula:

$$
L_{o a}=1.06 L_{w l}
$$

The number of rows in the captain's direction is $4, R_{o w}=4$, the length of the cabin of the amphibious landing craft is:

$$
L_{P}=R_{o w}+2.8=4+2.8=6.8
$$

The calculation formula of $6.8 \mathrm{~m}, 0.08$ and 0.10 was taken into the waterline length of the landing craft:

$$
L_{w 1}=L_{a}+L_{p}+L_{f}=0.08 L_{w 1}+6.8+0.10 L_{w 1}
$$

The solution can be obtained: $L_{w 1}=8.29 \mathrm{~m}$, So the landing boat length is $8.29 \mathrm{~m}$.

Calculate the total length of amphibious landing craft:

$$
L_{o a}=1.06 L_{w 1}=1.06 \times 8.29=8.79
$$

\section{Determination of the basic width of amphibious landing craft.}

The width of the amphibious landing craft can be calculated using the following formula:

$$
B=C_{o l} \times 0.5+1.8
$$

where: $C_{o l}$ is the number of rows in the direction of the boat.

The width of the waterline can be approximated by the following formula:

$$
B_{w 1}=0.88 B
$$

where: $B_{w 1}$------ Waterline breadth, the unit is $\mathrm{m}$;

$B$------ The width of an amphibious landing craft, the unit is $\mathrm{m}$.

$C_{o l}$ is 7 , the width of the amphibious landing craft can be calculated according to the following formula:

$$
B=C_{o l} \times 0.5+1.8=7 \times 0.5+1.8=5.3 \mathrm{~m}
$$

Calculation of waterline width:

$$
B_{w 1}=0.88 B=0.88 \times 5.3=4.66 \mathrm{~m}
$$




\section{Analysis and layout of power system of landing craft.}

\section{The basic layout of the cabin.}

The basic layout of the engine room is shown

below.

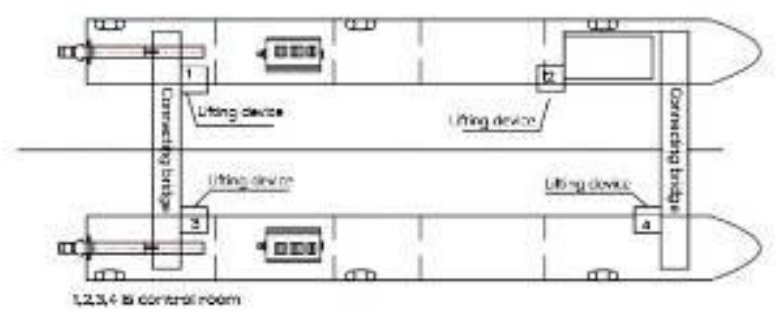

FIG. 4 cabin layout

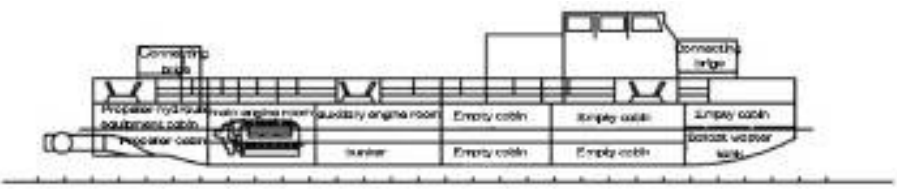

FIG. 5 cabin layout

\section{Speed calculation}

The effective power of amphibious landing craft is calculated using the following formula:

$$
P_{e}=R_{s} \times V_{s}
$$

where: $P_{e}$------ Effective power, the unit is $\mathrm{kW}$;

$R_{s-----}$ The total resistance of the ship, the unit is $\mathrm{KN}$;

$V_{s}$------speed ,the unit is $\mathrm{m} / \mathrm{s}$.

As the hull and a series of transmission devices consume a portion of the power, there is a question of efficiency; Propulsion power coefficient is landing craft effective $P_{e}$ and $P_{s}$, the ratio of the power from the host to P.C said:

$$
\begin{gathered}
P_{s}=P_{e} \div P . C \\
P . C=\eta_{g} \times \eta_{s} \times \eta_{r} \times \eta_{h} \times \eta_{o}
\end{gathered}
$$

where: $\eta_{g}$------ Efficiency of gearbox. $\eta_{s}$------ Efficiency of shafting

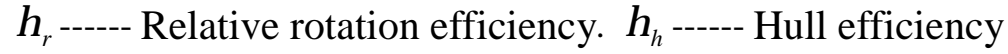

$\eta_{o}$------efficiency of open water propulsion

From the selection of diesel engine, can know the host of the power is $3900 \mathrm{kw}$, we use two hosts 
to drive the boat, total power is $7800 \mathrm{kw}$, by calculating the coefficient of the advance, advance coefficient is 0.52 , so the effective power should be calculated according to the following formula:

$$
2 \times 3900 \mathrm{kw} \times 0.52=4056 \mathrm{kw}
$$

By design, the total resistance of the landing craft is about $225 \mathrm{KN}$, and the maximum speed can be reached:

$$
4056 \mathrm{kw} \div 225=18.02 \mathrm{~m} / \mathrm{s}=35.04 \mathrm{kn}
$$

It is important to note that the resistance characteristics of catamaran is a body wave between the interference with each other. When in a strong interference resistance of catamaran is less than the sum of two separate pieces of body resistance ${ }^{[6]}$.

\section{The analysis of the host and selection}

The power system of this landing craft mainly refers to the engine that drives the power machine when it is in the water, and the motor that drives the crawler on land. Modem landing craft host type has a lot of, compared to several other kinds of diesel engine power plant, has good mobility, small size, high reliability, long service life, convenient maintenance, the characteristics of the economy $^{[7]}$, It is more suitable for our amphibious landing craft. Therefore, the power system of this landing craft chooses two diesel engines as the main engine.

The landing craft to hydrofoil, its higher requirements for quickening the landing craft, etc. After referring to a variety of civil and military hosts, we decided to choose the 20V 4000M93L Marine high speed diesel engine produced by German MTU company. On the one hand, it is widely used in government ships, military vessels and luxury yachts; On the other hand .The machine is a high-speed diesel engine with direct injection, water cooling, high pressure charging and irreversible four-stroke. High pressure common rail fuel injection system, three layers of wall exhaust pipe, sequential supercharging technology and shunt type cooling system design and other new technology such as its application on MTU4000 Marine high-speed diesel engine, it is a typical representative of Marine high-speed diesel engine.

\section{Model selection of propulsion systems}

The existing landing craft mainly USES three propulsion modes: tire propulsion, propeller propulsion and water jet propulsion. After comparison, considering the water jet propulsion with superior control performance and dynamic performance, stable operation and is not easy to damage, water jet propulsion ship, tonnage to the large-scale development and widely applicable form, the dominant position in the field of high speed high performance ship propulsion constantly consolidate and prospect of good advantages such as low speed transmission to extension ${ }^{[8]}$, The landing craft was propelled by a water jet.

\section{Mathematical model of water jet propulsion system. Water jet propulsion unit}

By using the following formula to calculate the basic properties of the water spray system, such as thrust, shaft power, torque, torque, etc.:

$$
\begin{aligned}
& T_{B}=\left(1-t_{B}\right) \cdot \rho \cdot Q_{B} \cdot V_{B} \cdot(k \cdot \cos \varphi-\alpha) \\
& P_{B}=\gamma \cdot Q_{B} \cdot H / \eta_{0} \\
& M_{B}=P_{B} / N_{B} \\
& \eta_{P T}=\eta_{P C} \cdot \eta_{0} \\
& k=V_{j} / V_{S}
\end{aligned}
$$

Considering that the thrust of the sprinkler system is compatible with the total resistance of the landing craft, After our calculation, the total resistance is about $160 \mathrm{KN}$, and the thrust of the sprinkler system should be no less than $160 \mathrm{KN}$ when running at the rated power of the landing craft. 
According to the main engine power and transmission efficiency, the shaft power is $2028 \mathrm{~kW}$.

\section{Piping system}

The basic parameters of the pipeline system are: the system efficiency of the lift, the water jet propulsion system, the pipe loss coefficient of the water jet propulsion system, etc.

Reducing pipe loss is the key to improve water efficiency. In the design, the pipe should be short and the elbow is small, and the pipe resistance can be increased by avoiding vacuole on the inlet side. Pipeline loss can be determined by pipeline experiment or subsection calculation. The water pump efficiency of the landing craft was 0.90 and the shaft system efficiency was 0.97 .

In view of the above results, in reference to the various types of hydraulic system after we analyzed, finally selected for the research and development of Chinese shipping and Marine engineering design and research institute of MARIC - HL series mixed flow hydraulic propeller, The technical specifications for this series of water jet are between $50 \mathrm{~kW}-6000 \mathrm{~kW}$ (host input power), and we choose the $2240 \mathrm{~kW}$ type of water jet propeller. It applies to ships mounted on $25 \mathrm{kn}$ to $55 \mathrm{kn}$.

\section{Optimization design of traditional system}

Because we designed by amphibious landing craft have the double function of road and land surface, so the corresponding transmission mechanism consists of two sets: the water sailing drive, power for the hydraulic propeller; The land transmission system is the driving force for the crawler. We have consulted a number of information and related products designed a set of transmission mechanism, as shown in figure 6:

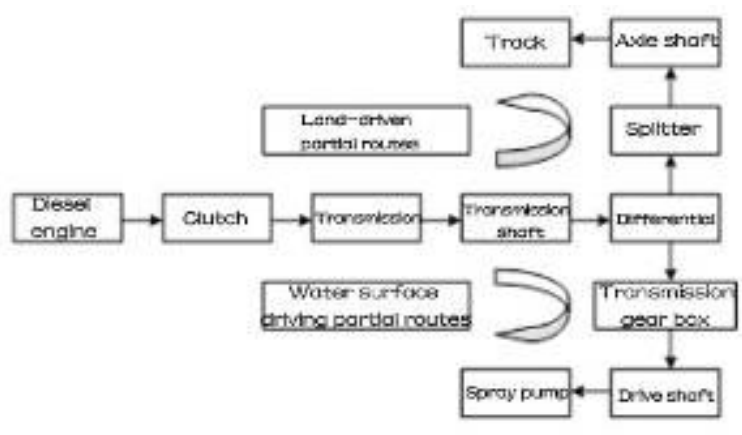

FIG. 6 transmission flow

\section{Track composition and force calculation}

\section{Track composition}

Track composition as shown in Figure 7:

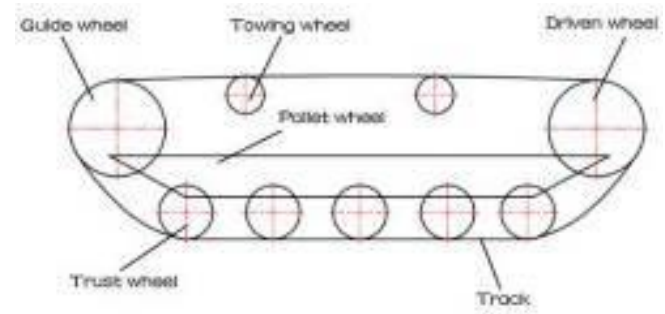

FIG. 7 Track composition

\section{Track force calculation}

The hull is under the influence of propulsion and resistance, from the beginning of the speed down and contacting with the water surface to a stable speed, the water resistance can be obtained by the following equation: 


$$
R_{f} \cdot d_{t}=S_{1} \cdot v_{0}^{2} \cdot d_{t}
$$

solution:

$$
R_{f}=S_{1} \cdot v_{0}^{2}
$$

For water viscous resistance, there is:

$$
R_{v p}=k \cdot S_{2} \cdot \rho \cdot v_{0}^{3}
$$

where: $S_{1}$------Water surface area

$S_{2}$ --Wet part area

$\rho$------Liquid density $k$------ Constant

The total resistance experienced by the above equation of crawler is:

$$
R_{v p}+R_{f}=S_{1} \cdot v_{0}^{2}+k \cdot S_{2} \cdot \rho \cdot v_{0}^{3}
$$

\section{Analysis of Feasibility}

\section{Economic performance analysis}

\section{Analysis of Economic Performance of Ship Hydrofoil}

When ship is at foil borne, The great part of the hull weight is supported by the lift of the hydrofoil, The remaining small part is supported by the buoyancy of the four pontoons, landing craft drastically reduced draught. Due to reduced draught, Wet area is also reduced, frictional resistance is reduced, shape resistance and wave-making resistance are also greatly reduced, making the total resistance reduced. The resistance of the landing craft is only about half that of a gliding boat or a high-speed catamaran with the same tonnage and the same speed, that is, it can obtain a higher speed with less power and greatly improve the economy. The economic speed of the landing craft range approximately $55-75 \mathrm{~km} / \mathrm{h}$, and the speed of the ultra-high-speed hydrofoils is approximately $100 \mathrm{~km} / \mathrm{h}(54 \mathrm{kn})$. The maximum cruise speed we designed is $30 \mathrm{kn}$. In addition, the disturbance of the wave to the landing craft is relatively small. The correctly designed self-stable hydrofoil system has a suitable motion response in the wind and waves. Compared with a gliding boat, a catamaran, or a hovercraft with the same scale and the same speed, its pitching, rolling and heave motion are all smaller ${ }^{[9]}$.

Compared to the traditional landing craft, our landing craft designed can perform amphibious operations at high speeds, which greatly improves the economy and efficiency of landing craft's overall navigation. Through the mutual cooperation of the hydrofoil mechanism and the hull track structure, the landing craft quickly completes the transition of the navigation state between the shallow sea and the land, which greatly reduces the energy consumption and increases the economic efficiency of the ship. The social benefit is huge and the economic prospect is considerable.

\section{Analysis of Economic Performance of Ships Crawler}

Compared to the traditional landing craft, the excess transmission part of the traditional landing craft will be subject to greater resistance due to water surface impact during navigation, which will increase fuel consumption accordingly. By installing a buoyancy tank on the crawler's front and back, the crawler will reduce the resistance and provide a part of buoyancy for the landing craft. As a result, the whole energy consumption of the landing craft will be partially reduced. 
During land travel, landing craft can smoothly, quickly and safely pass through a variety of complex road conditions through the use of track which is more economical and efficient. Due to the larger grounding area, the tank's ability to pass through the soft and muddy road surface is increased, and the amount of sinking is reduced, making it possible for the landing craft to complete the beach-climbing process with low energy consumption and high stability, and to keep going.

In summary, the track plays a different role in the switching of multiple working states of the hull, so that each working state is organically integrated, and the overall efficiency and speed of the landing craft will be greatly improved.

\section{Feasibility of safety}

\section{Hull restoring moment}

Ship get heeling angle $\theta$ with the restoring moment produced by hull, the shape restoring moment of the hull:

$$
M_{S}=\left(\operatorname{disp}+f_{x}\right) \cdot Z_{m} \cdot \sin \theta
$$

where: disp---- Constant of Amphibious landing craft hull displacement at foil borne, united t;

$f_{x}$------displacement provided by landing craft pontoons, united t;

$Z_{m}$------transverse metacenter height of amphibious landing craft in wing state, united $\mathrm{m}$. is:

Therefore, after the ship produces heeling angle $\theta$, the restoring moment generated by the hull

$$
\begin{array}{r}
M_{h}=M_{s}-\left(\text { weight }+I_{d}\right) \cdot Z_{g} \cdot \sin \theta \\
=\left(\text { disp }+f_{x}\right) \cdot Z_{m} \cdot \sin \theta-\left(\text { weight }+I_{d}\right) \cdot Z_{g} \cdot \sin \theta
\end{array}
$$

where: Weight ------ weight of the amphibious landing craft hull, united t;

$I_{d}$------weight of track, united $t$;

$Z_{g}$------ height from the actual center of gravity to the assumed center of gravity of the amphibious landing craft, united $\mathrm{m}$.

Weight and $I_{d}$ The sum of the two is equal to the sum of the hull displacement and the wing lift. All heeling moments acting on the ship are assumed to be based on the center of gravity pointed $S$ ( IE, the intersection of the baseline, the ship's cross section and the mid-longitudinal section).

\section{Hydrofoil lift calculation}

hydrofoil lift $L=\frac{1}{2} \cdot \rho \cdot v^{2} \cdot s \cdot c \cdot C_{L}$ 。

where: $C_{L}$ is constant of hydrofoil lift, $v$ is ship speed, taking the landing boat's maximum speed $v=25 \mathrm{~m} / \mathrm{s}, \quad s$ and $c$ are the expanded length of the hydrofoil and the length of the chord, taking $s=3.72, c=0.78$, taking $\rho$ water density. 
The hydrofoil lift coefficient can be calculated as follows: $C_{L}=\frac{k_{\varphi} \cdot \frac{\partial C_{L}}{\partial \alpha} \cdot\left(\alpha+\alpha_{0}-\Delta \alpha_{0}-\varphi \cos \beta\right)}{1+\frac{\partial C_{L}}{\partial \alpha} \cdot \frac{k_{\varphi}}{\pi \lambda} \cdot(1+\tau) \cdot \xi\left(\frac{h}{\lambda}\right)}$ Where: $\frac{\partial C_{L}}{\partial \alpha}$------ lift coefficient derivative to angle of attack, taking $\frac{\partial C_{L}}{\partial \alpha}=5.5$;

$k_{\varphi}=1-(0.5+\bar{t}) \exp \left[-2 \bar{h}^{0.6}\right]------$ influence of the free liquid derivative to the lift system, where, $\bar{t}=t / c$ is relative thickness of hydrofoil, $t=0.0325 m, \bar{h}=h / c$ is relative submergence of hydrofoil, taking $\bar{h}=2, c$ is chord length of hydrofoil ;

$\alpha$------angle of attack of hydrofoil, taking $\alpha=2^{\circ}, \quad \alpha_{0}=1.74$;

$\bar{f}$------ zero lift angle, $\bar{f}=f / c$ is the relative degree of curvature of the hydrofoil according to the design selection $\bar{f}=0.15$;

$\Delta \alpha_{0}=\frac{\bar{t}}{2}\left(\frac{1}{k_{\varphi}}-1\right)$------ variation of airfoil zero lift angle caused by free liquid surface;

$\varphi$------the pitch angle (trimming is positive);

$\beta$------ oblique angle, for cutting hydrofoil;

$\lambda$------ aspect ratio of hydrofoil;

$\tau=0.09 \sqrt{\lambda}-0.04$------ correct coefficient of influence of hydrofoil shape on slant angle and induced $\operatorname{drag} \xi(\bar{h} / \lambda)$------ hydrofoil soak depth and the influence of the wingspan on the slope of the flow field, when

$$
0.02<\bar{h} / \lambda<1.0 \mathrm{H}, \quad \xi(\bar{h} / \lambda)=0.85+\frac{0.16}{\sqrt{\bar{h}} / \lambda}
$$

\section{Hydrofoil-generated restoring moment}

In order to improve the accuracy of the calculation, the hydrofoil is sliced in the direction of the length of the protuberance, and the restoring moment generated by each slice is calculated, and then integrated along the direction of the extension to obtain the restoring moment of the entire hydrofoil. 。

After ships get heeling angle $\theta$, The lift of a slice ds at one side of the hydrofoil

$$
d L I=\frac{1}{2} \cdot \rho \cdot v^{2} \cdot d s \cdot c \cdot d C_{L i}
$$

The restoring moment produced by the slice DS is:

$$
d L I=\frac{1}{2} \cdot \rho \cdot v^{2} \cdot d s \cdot c \cdot d C_{L i}
$$

The restoring moment produced by the slice $d s$ is: 


$$
d M_{F I}=d L I \cdot a r m I
$$

where: $\operatorname{armI}$ is the vertical distance assuming that the point of gravity $\mathrm{S}$ is away from the slice $d s$ lift action line, that is, the lift arm of the slice $d s$.

After the ship gets heeling angle $\theta$, the restoring moment generated by the water immersed portion on the left side of the hydrofoil is:

$$
M_{F I}=-\int_{0}^{s} d M_{F I}
$$

Similarly, the restoring moment generated by the water immersed part of the other side of the hydrofoil is:

$$
M_{F r}=-\int_{0}^{s} d M_{F r}
$$

From this, it can be seen that after the ship gets heeling angle $\theta$, the restoring moment produced by the hydrofoil is:

$$
M_{F}=M_{F I}+M_{F r}
$$

\section{Total restoring moment for ship in amphibian foil borne}

Due to the foil borne, the general catamaran is at a small water surface, and the hull recovery torque is relatively small. Although the hydrofoil can also provide a restoring torque, the restoring moment of the sum of the two can still be negative. The recovery torque provided by the pontoon just solves the problem of insufficient stability on the surface of the small waterline. When the ship appears heeled, the landing craft we designed has enough restoring torque to allow the vessel to return to the floating state, which is safe enough.

\section{Conclusion}

Through the structural and functional improvements made to the defects of ordinary landing craft's equipment or devices, the operational efficiency of the landing craft has been improved, and the efficiency of construction operations in the South China Sea has been greatly improved. In view of the structural and functional transformation to ordinary landing craft, this article firstly uses the analogy method to avoid the defects of other devices or equipment by referring to the data. Secondly, through the facility planning and design method, we can do reasonable structure design and rational configuration to the "multifunctional crawler type high-efficiency hydrofoil landing craft", and then use calculation method designed combined with structure designed and related calculation formulas to achieve the theoretical maximum design optimization, and then use the software application method for graphic design and analysis, and finally through the simulation test method to test the design works, and Problems arise to feedback and optimize. The results of feasibility analysis show that the model can effectively avoid the deficiencies of ordinary landing craft equipment and has good practicality. The model constructed by the project has implications for other similar ability evaluation problems.

\section{References}

[1] Li Wan-nan. The Opportunities and Challenges to China's Construction of the "21st-Century Maritime Silk Road": With Some Advice for Responding Measures [J]. Journal of China's Neighboring Diplomacy 2015(01)

[2] JIANG Jun. The development of Chinese hovercraft [J]. Shipborne Weapons. 2004(10)

[3]Wang Wei-xiang. Weng Ya-dong. Application and development of foreign hovercraft [J]. World 
Rubber Industry. 2008(12)

[4] Song Guo-hua. The overall performance design of the catamaran [J]. SHIP \& BOAT 1998 (01) [5] XU Er-xu. ZHOU Kun-fang. MING Hai. Research on the development and performance characteristics of high-speed catamaran ships. Science and technology association of Guangdong province [G]. Thematic compilation. 2014(05)

[6]WANG Cheng-yi. Characteristics and application of high speed catamaran resistance [J]. China shipbuilding. 1994(08)

[7] REN Chuan-ti. Study on the green degree evaluation system of ship power plant [D].2009(06)

[8]DING Jiang-ming. Research and application of water jet propulsion technology at home and abroad. School of transportation, wuhan university of technology.2013 (08).

[9] ZHANG Da-xiong. Hydrofoil ship principle features and its use and maintenance [J]. JIANGSU SHIP. 2000(03) 